\title{
Global Vegetable Intake and Supply Compared to Recommendations: A Systematic Review
}

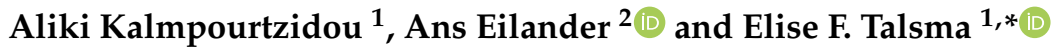 \\ 1 Division of Human Nutrition and Health, Wageningen University, PO Box 17, 6700 AA Wageningen, \\ Gelderland, The Netherlands; alikikalb@hotmail.com \\ 2 Unilever Foods Innovation Centre, Bronland 14, 6708 WH Wageningen, Gelderland, The Netherlands; \\ ans.eilander@unilever.com \\ * Correspondence: Elise.Talsma@wur.nl
}

Received: 3 May 2020; Accepted: 21 May 2020; Published: 27 May 2020

\begin{abstract}
Low vegetable intake is associated with higher incidence of noncommunicable diseases. Data on global vegetable intake excluding legumes and potatoes is currently lacking. A systematic review following Preferred Reporting Items for Systematic Reviews and Meta-Analyses (PRISMA) guidelines was conducted to assess vegetable consumption and supply in adult populations and to compare these data to the existing recommendations ( $\geq 240 \mathrm{~g} /$ day according to World Health Organization). For vegetable intake data online, websites of government institutions and health authorities, European Food Safety Authority (EFSA) Comprehensive European Food Consumption Database, STEPwise approach to surveillance (STEPS) and Pubmed/Medline databases were searched from March 2018 to June 2019. Vegetable supply data was extracted from Food Balance Sheets, Food and Agriculture Organization Corporate Statistical Database (FAOSTAT), 2013. Vegetable intake was expressed as means and $95 \%$ confidence intervals. Data were summarized for each region by calculating weighted means. Vegetable intake and supply data were available for 162 and 136 countries, respectively. Weighted mean vegetable intake was $186 \mathrm{~g} /$ day (56-349 g/day). Weighted mean vegetable supply was $431 \mathrm{~g} /$ day $(71-882 \mathrm{~g} /$ day). For $88 \%$ of the countries vegetable intake was below the recommendations. Public health campaigns are required to encourage vegetable consumption worldwide. In the $61 \%$ of the countries where vegetable supply is currently insufficient to meet the recommendations, innovative food system approaches to improve yields and decrease post-harvest losses are imperative.
\end{abstract}

Keywords: vegetables; vegetable consumption; dietary intake; vegetable supply; global

\section{Introduction}

The incidence of chronic, noncommunicable diseases (NCDs) (mainly cardiovascular diseases (CVDs), cancer, chronic respiratory disease and diabetes) is increasing rapidly and is having a significant impact on society, economy and health [1-4]. Currently, 70\% of deaths are caused by NCDs worldwide [1]. A major risk factor for NCDs is an unhealthy diet, including low vegetable consumption $[4,5]$.

Multiple studies indicated a positive relation between vegetable intake and reduction of CVDs [3,6-18]. In a meta-analysis by Zhan et al. (2017) [18], the pooled relative risk (RR) for CVDs between highest versus lowest vegetable intake category was 0.87 (95\% CI: 0.83-0.91), which indicates a decreased CVD risk with increasing vegetable intake. Associations between vegetable intake and adiposity [2,19-21], type 2 diabetes [2,22-29], chronic respiratory diseases [30,31] and cancer [2,8,32-38] are less consistent. The benefits of vegetables on prevention of NCDs can be explained by the relatively high content of micronutrients, antioxidant compounds, polyphenols and fibers in vegetables that 
may counteract the biochemical processes leading to onset of CVDs and other NCDs [39]. As different vegetable categories differ in nutritional composition, the associations with health outcomes may differ as well [39].

Although the health benefits of fruits and vegetables are usually studied together in most studies $[1,11,13,15,16,23,25,32,34]$, it is recommended that the benefits of these two food groups are assessed separately. Fruits and vegetables share health benefits due to common phytochemicals (e.g., phenolics, flavonoids, carotenoids), vitamins (e.g., vitamin C, folate, pro-vitamin A), minerals (e.g., potassium, calcium, magnesium) and fibers, but bioactive compounds differ widely in composition and ratio between fruits and vegetables [40-43]. Moreover, fruits have usually a higher concentration of sugars than vegetables, while vegetables are more likely to have a higher concentration of fibers and proteins [40]. Particularly when fruit juices are included in fruit measurements, beneficial effects of fruits alone or in combination with vegetables may not become apparent due to higher intakes in sugar and energy from fruit juices [44]. In fact, studies that have separated fruit and vegetable groups have shown differences in health outcomes [6,22,24,36,38,40,45-47]. For instance, in a study by Villegas et al. (2008), the increased intake of specific vegetable groups was significantly inversely associated with the type 2 diabetes risk, while this association was not found for increased fruit intake in Chinese women [24].

According to World Health Organization (WHO) and Food and Agriculture Organization (FAO) guidelines (2003), the recommended consumption of fruits and vegetables is at least $400 \mathrm{~g} / \mathrm{day}$ [48]. While it is generally believed that vegetable intake is inadequate in most countries [49-52], there is currently no systematic review that focuses solely on vegetable intake to confirm these assumptions. The Global Burden of Disease (GBD) Study 2010 assessed vegetable intake and concluded that the intake was generally too low to minimize the risk of chronic diseases $[49,50]$. However, in this study vegetable intake was combined with that of legumes and not all data included was assessed at the individual level. Hall et al. (2009) [52] concluded that low vegetable and fruit consumption is higher in low- and middle-income countries, but did not separate fruit and vegetable intake.

Therefore, the main aim of the current study is to systematically review the vegetable consumption in adult populations of 18 years and older globally and to compare these data to the existing recommendations and to vegetable supply data.

\section{Materials and Methods}

\subsection{Definitions}

The definition of "vegetables" varies significantly among different countries and regions and consequently local recommendations on vegetable intake differ. In the current review, the definition for "vegetables" by WHO/FAO is followed, which excludes potatoes, tubers, legumes and pulses [53].

We derived a vegetable intake recommendation from the global recommendation by FAO/WHO (2003) of $\geq 400 \mathrm{~g} /$ day ( 5 servings of $80 \mathrm{~g}$ ) for fruit and vegetables, as there is no specific guideline for vegetables alone [48]. As most countries follow the FAO/WHO guidelines and the majority suggest that at least three servings ( $240 \mathrm{~g} /$ day) should come from vegetables [54,55], we set the vegetable intake recommendation at $\geq 240 \mathrm{~g} /$ day.

\subsection{Search Strategy}

The search was conducted according to the Preferred Reporting Items for Systematic Reviews and Meta-Analyses (PRISMA) guidelines from March 2018 to June 2019 (see Supplementary Materials, Table S1) [56]. Data about vegetable intake was preferably taken from national nutrition surveys in order to extract the most representative vegetable intake data. Therefore, we first searched these surveys per country from government websites and online databases from health authorities [57,58]. The European Food Safety Authority (EFSA) Comprehensive European Food Consumption Database was used as a guide for reviewing the existing national nutrition surveys in Europe [59]. For some European 
countries for which the national survey reports did not report vegetable intake separately from potatoes and legumes, vegetable intake data was taken from the EFSA database. The STEPwise approach to surveillance (STEPS) database was also consulted for available vegetable intake data. STEPS is a simple, standardized method for collecting, analyzing and disseminating data regarding surveillance of NCD risk factors, with a non-itemized Food Frequency Questionnaire (FFQ) on vegetable intake. STEPS surveys are usually initiated and conducted by Ministry of Health officials in collaboration with local technical partners [4].

When for a country no nationally representative survey with relevant vegetable intake data was retrieved, a literature search in PubMed was conducted. The search string was a combination of the following terms: "dietary intake" OR "food consumption" OR "vegetable intake" OR "vegetable consumption" AND "country name". There were no language restrictions in the overall search. Papers were screened and selected according to titles and abstracts, followed by a full-text review for final inclusion, using the following inclusion criteria:

1. Data from adult populations aged $\geq 18$ years.

2. Free living, healthy population. Disabled people, populations with specific diseases or with special dietary needs (pregnant and lactating women, athletes) were excluded.

3. National or population-based surveys/studies. In case these were not available, baseline data or data from a control group, belonging to a healthy general population, of controlled trials were included.

4. Surveys/Studies conducted from the year 2000 onwards and published until June 2019.

5. Sample size of participants $\geq 100$.

6. Surveys/Studies in which vegetable intake in adults at individual level were included (therefore, studies estimating vegetable intake per capita or at household level were excluded)

7. Countries and continent regions included were derived from the UN Geoscheme created by UN Statistics Division and World Atlas [57,58].

\subsection{Data Extraction}

Data extraction was conducted by two independent researchers to eliminate data extraction errors. Means and 95\% confidence intervals (95\% CI) were mainly extracted; if not available, medians, Standard Deviations (SD), percentiles, ranges, and Standard Errors (SE) were extracted. Additionally, data about gender, age, sample size, year of survey conduct, year of publication, study type, sample representativeness and vegetable intake assessment methodology were extracted.

\subsection{Quality Assessment of the Data}

Representativeness was defined in three levels. A sample was considered highly representative when: 1) there was a statement by the authors of the survey/study that the sample was representative for the target population, but also covered all or most of the regions of a country; 2) its representativeness was addressed by the methodology used and the stratification of the sample (distribution of sample according to age, gender, education, regions etc.). A sample was considered moderately representative when at least one of the above criteria was followed, but participants from most of the country's regions were not included. A sample was not considered representative when none of the representativeness criteria were met [60].

\subsection{Data Analysis}

Vegetable consumption was expressed in grams per day. Descriptive statistics were used for the analysis of vegetable intake. For six countries for which no data on vegetable consumption alone were found, we used data where vegetable and fruit intake were reported together and assumed that vegetable consumption covered $60 \%$ of the intake according to WHO/FAO recommendation about vegetable and fruit intake. When means and 95\% CIs were expressed for subgroups of gender, age 
or ethnicity, a weighted mean and 95\% CI were calculated using the mean, 95\% CI and the number of participants of each group. When data were not expressed in means and $95 \%$ CIs, then data were converted using the following equations.

1. For the conversion of medians and ranges into means [61]:

$$
\overline{\mathrm{x}}=(\mathrm{a}+2 \mathrm{~m}+\mathrm{b}) / 4
$$

where $\overline{\mathrm{x}}=$ mean, $\mathrm{a}=$ minimum, $\mathrm{b}=$ maximum and $\mathrm{m}=$ median.

2. For conversion of median and 25th and 75th percentiles into means [62]:

$$
\overline{\mathrm{x}}=(\mathrm{q} 1+\mathrm{m}+\mathrm{q} 3) / 3
$$

where $\bar{x}=$ mean, $\mathrm{q} 1=\mathrm{P} 25, \mathrm{~m}=$ median, $\mathrm{q} 3=\mathrm{P} 75$.

3. For mean and SE into 95\% CIs [63]:

$$
95 \% \mathrm{CI}=\overline{\mathrm{x}} \pm 1.96 * \mathrm{SE}
$$

4. For mean and SD into 95\% CIs [63]:

$$
95 \% \mathrm{CI}=\overline{\mathrm{x}} \pm 1.96 * \mathrm{SD} / \sqrt{\mathrm{n}}
$$

5. For 25th and 75th percentiles into 95\% CI [62], first a conversion was made into SD and then into $95 \%$ CI following the equation above (4):

$$
\mathrm{SD}=(\mathrm{P} 75-\mathrm{P} 25) / 1.35
$$

6. For 5th and 95th into 95\% CI [62], first a conversion was made into SD and then into 95\% CI following the equation above (4):

$$
\mathrm{SD}=(\mathrm{P} 95-\mathrm{P} 5) / 3.3
$$

For each region, we calculated a weighted mean vegetable intake where we used the adult population of 18 years and older in 2013 as derived from United Nations Children's Fund (UNICEF) State of the World's Children report, 2015 [64].

\subsection{Vegetable Supply Data}

Vegetable supply per country was extracted and calculated according to data from the most recent food balance sheets by Food and Agriculture Organization Corporate Statistical Database (FAOSTAT) (2013) [65]. The vegetable supply was the sum of the supply data from the food categories onions, tomatoes and their products, peas and other vegetables: and excluded legumes, potatoes, tubers and pulses [65]. Vegetable supply was converted from $\mathrm{kg} / \mathrm{year} / \mathrm{capita}$ to $\mathrm{g} /$ day/capita in order to compare results with the vegetable intake data. For each region, we calculated a weighted mean vegetable supply where we used the adult population in 2013 as weighing factor.

\section{Results}

\subsection{Data Availability, Representativeness and Dietary Assessment Methodology}

The systematic search yielded initially 3247 publications (Figure 1). After abstract and title screening, 558 publications were assessed for eligibility. The final review dataset included 160 publications with studies measuring vegetable intake in 162 out of 235 countries, covering $93 \%$ of the world's adult population. Vegetable supply data were available for 136 out of the $162(84 \%)$ countries with vegetable intake data; for the smaller countries vegetable supply data was mostly lacking.

The surveys/studies included in this review had a high sample representativeness, with only $28(17 \%)$ with a non-representative sample and six (4\%) with no information about sample 
representativeness (see Supplementary Materials, Table S2). The sample size of the surveys/studies ranged from 100 subjects in Jamaica to 140,859 in China.

The most frequently used method to assess vegetable intake was a (semi-) quantitative FFQ (65\%), which also includes the STEPS methodology which was used in most African, Latin American and Oceanian countries. Vegetable intake data in high-income countries were mostly from national nutrition surveys in which a combination of $24 \mathrm{~h}$ dietary recalls and FFQs were used (see Supplementary Materials, Table S2).

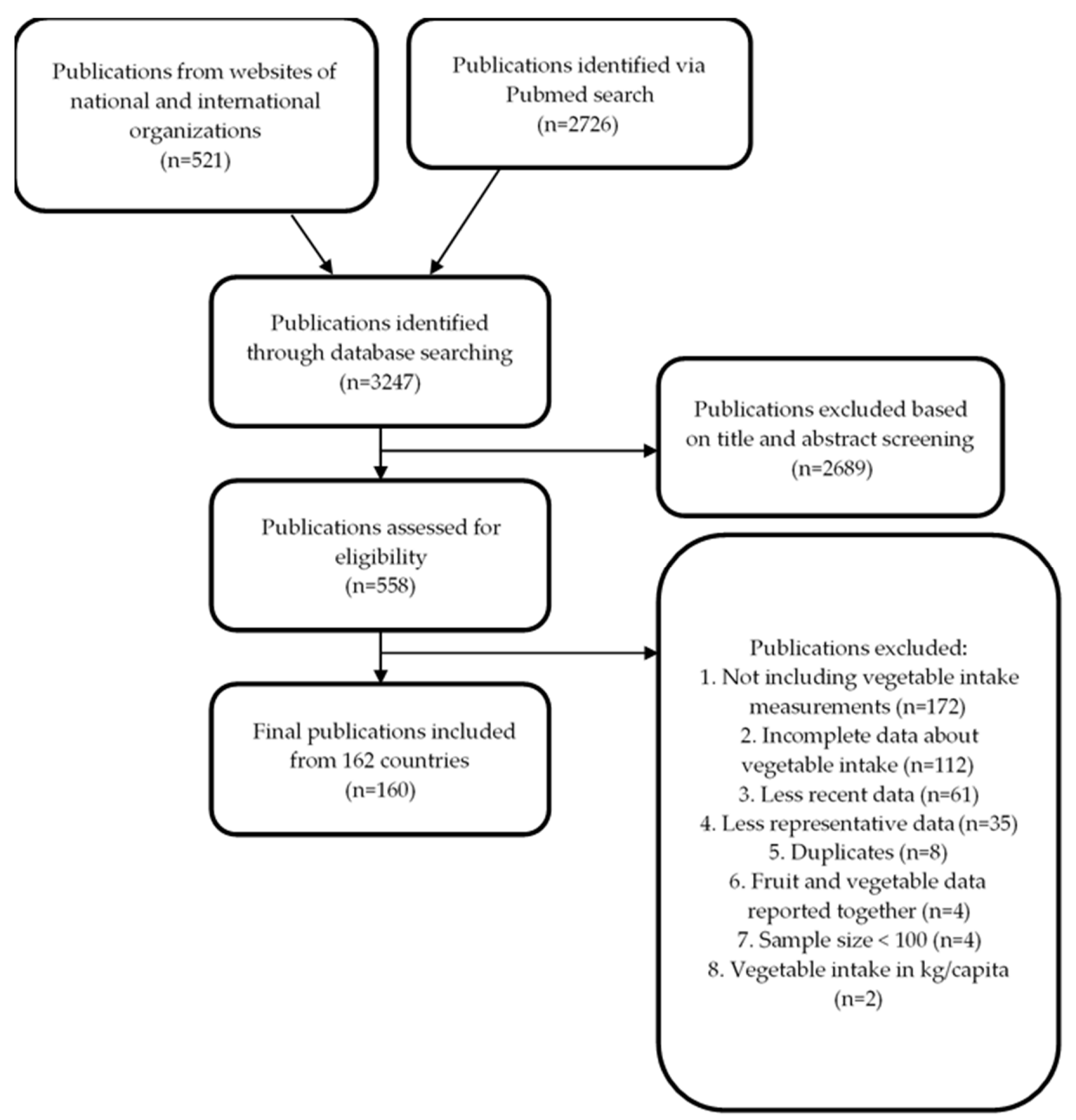

Figure 1. Flowchart of the review process for the selection of the final surveys/studies assessed.

\subsection{Global Vegetable Intake and Supply}

Based on data of 162 countries, the weighted mean vegetable intake was $186 \mathrm{~g} /$ day and ranged from $56 \mathrm{~g}$ /day in Central America to $349 \mathrm{~g} /$ day in East Asia (Table 1). Based on data from 136 countries, the weighted mean global vegetable supply was $431 \mathrm{~g} /$ day and ranged widely among the different regions from $71 \mathrm{~g} /$ day in Melanesia to $882 \mathrm{~g} /$ day in East Asia. Details of vegetable intake and supply per country can be found in the supporting information, Table S2. Asia was the continent with the highest vegetable consumption, where 10 countries $(29 \%)$ met the recommendations, while in Oceania $2(11 \%)$, Africa $3(7 \%)$, Europe $4(11 \%)$ and America $1(7 \%)$ countries had an adequate consumption of vegetables (Table 1). In Europe, 26 out of $36(72 \%)$ and in Asia, 19 out of 31 countries $(61 \%)$ had an adequate vegetable supply to meet the vegetable recommendation of $\geq 240 \mathrm{~g} / \mathrm{day}$; whereas in Africa 5 out of 39 countries $(13 \%)$ had a sufficient vegetable supply to meet the recommendation. 
Table 1. Vegetable intake expressed in average and range (g/d) and number (\%) of countries according to vegetable servings/d per continent region [57,58].

\begin{tabular}{|c|c|c|c|c|c|c|c|c|c|c|}
\hline \multirow[b]{2}{*}{ Continent } & \multirow[b]{2}{*}{ Region } & \multirow[b]{2}{*}{$\begin{array}{l}\text { Number of } \\
\text { countries in the } \\
\text { Region }\end{array}$} & \multicolumn{4}{|c|}{ Vegetable intake per Region (g/day) } & \multicolumn{4}{|c|}{ Vegetable Supply per Region (g/day) } \\
\hline & & & $\begin{array}{l}\text { Countries with } \\
\text { Data (n) }\end{array}$ & $\begin{array}{l}\text { Weighted } \\
\text { Mean }\end{array}$ & Range & $\begin{array}{l}\text { Countries with } \\
\text { Vegetable Intake } \\
\geq 240 \mathrm{~g} / \text { day (\%) }\end{array}$ & $\begin{array}{c}\text { Countries } \\
\text { with Data } \\
\text { (n) }\end{array}$ & $\begin{array}{l}\text { Weighted } \\
\text { Mean }\end{array}$ & Range & $\begin{array}{c}\% \text { of Vegetable } \\
\text { Supply } \\
\text { Consumed }\end{array}$ \\
\hline \multirow{4}{*}{ Asia } & West & 11 & 11 & 144 & $89-256$ & 9 & 9 & 545 & $202-765$ & $26^{1}$ \\
\hline & East & 8 & 6 & 349 & $80-357$ & 67 & 6 & 882 & $149-969$ & $40^{1}$ \\
\hline & Southeast & 13 & 11 & 153 & $91-400$ & 27 & 10 & 190 & $92-577$ & $80^{4}$ \\
\hline & South & 8 & 7 & 81 & $62-304$ & 29 & 6 & 264 & $75-315$ & $31^{3}$ \\
\hline \multirow{4}{*}{ Europe } & East & 13 & 12 & 270 & $83-382$ & 25 & 12 & 323 & 109-956 & $84^{2}$ \\
\hline & North & 17 & 10 & 132 & $72-227$ & 0 & 10 & 270 & 192-339 & 49 \\
\hline & South & 17 & 9 & 167 & $128-240$ & 11 & 8 & 453 & $221-662$ & 37 \\
\hline & West & 9 & 6 & 123 & 95-207 & 0 & 6 & 269 & 239-379 & 46 \\
\hline \multirow{4}{*}{ America } & Central & 7 & 2 & 56 & $1-88$ & 0 & 2 & 145 & $127-156$ & 39 \\
\hline & South & 12 & 8 & 156 & $48-263$ & 13 & 8 & 148 & 64-197 & $106^{3}$ \\
\hline & Caribbean & 29 & 14 & 104 & $38-163$ & 0 & 9 & 102 & 53-252 & $102^{1}$ \\
\hline & North & 6 & 4 & 108 & $92-226$ & 0 & 4 & 277 & 153-474 & 39 \\
\hline \multirow{4}{*}{ Oceania } & Australasia & 5 & 3 & 126 & $23-127$ & 0 & 2 & 295 & $283-357$ & 43 \\
\hline & Melanesia & 7 & 3 & 73 & $64-248$ & 33 & 2 & 71 & 37-142 & $103^{1}$ \\
\hline & Micronesia & 8 & 5 & 122 & $32-216$ & 0 & 1 & 155 & 155-155 & 78 \\
\hline & Polynesia & 12 & 7 & 196 & $72-417$ & 14 & 2 & 110 & $67-140$ & $178^{1}$ \\
\hline \multirow{5}{*}{ Africa } & North & 11 & 5 & 122 & 88-170 & 0 & 4 & 434 & $230-531$ & 28 \\
\hline & East & 20 & 14 & 98 & 28-304 & 7 & 10 & 86 & 48-206 & $114^{5}$ \\
\hline & Central & 9 & 6 & 103 & $25-304$ & 17 & 6 & 134 & 21-294 & $77^{4}$ \\
\hline & West & 17 & 14 & 123 & $25-216$ & 7 & 14 & 122 & 46-331 & $101^{6}$ \\
\hline & South & 5 & 5 & 135 & $88-168$ & 0 & 5 & 114 & 54-119 & $118^{4}$ \\
\hline
\end{tabular}

${ }^{1-7}$ Number indicates the number of countries in the region where the vegetable supply was higher than the vegetable intake. 
Figure 2 provides an overview of the vegetable intake and supply data against the vegetable recommendations of $\geq 240 \mathrm{~g} /$ day based on data of 136 countries. Only 10 out of 136 countries (7\%) have an adequate intake and adequate supply of vegetables, whereas in 119 of the 136 countries $(88 \%)$ vegetable intake is below the recommendations. Moreover, in 73 of these 119 countries (61\%) vegetable supply is inadequate to meet the recommendations. For seven countries, vegetable intake was adequate, but vegetable supply data were below $240 \mathrm{~g} / \mathrm{day}$.

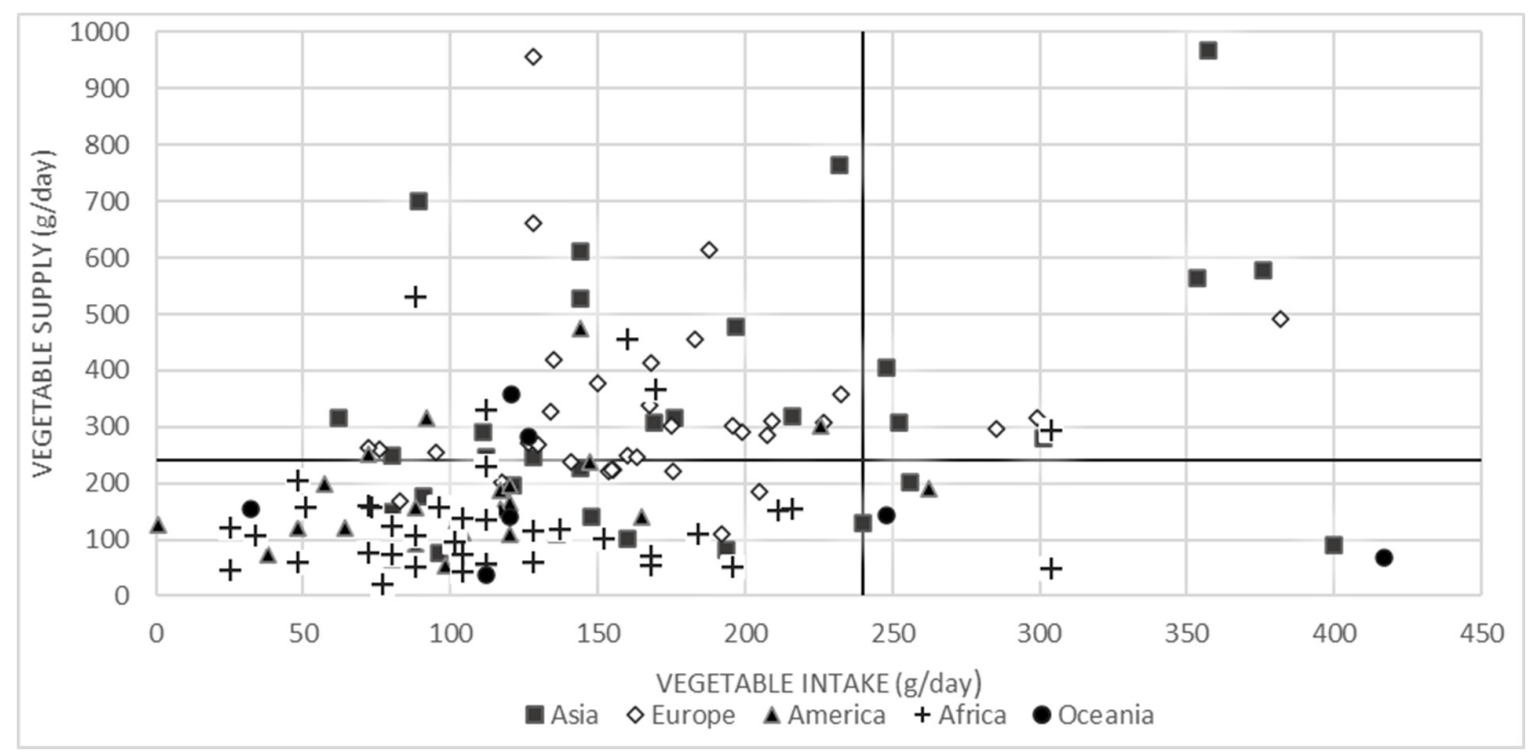

Figure 2. Vegetable intake and supply per country benchmarked against the vegetable recommendations of $240 \mathrm{~g} /$ day $(\mathrm{WHO} / \mathrm{FAO})$.

\subsection{Asia}

Vegetable intake data was absent for Central Asia. Among the other Asian regions, weighted mean vegetable intake ranged from $81 \mathrm{~g} /$ day (mean lowest and highest intake in region countries: 56, $304 \mathrm{~g} /$ day) in South Asia to 349 (80, 357) g/day in East Asia. In East Asia four out of six countries (67\%) met the recommendations for vegetable intake, whereas this was the case for $9-29 \%$ of the countries in the other Asian regions (Table 1). The weighted mean vegetable supply ranged widely within and among the Asian regions; from $190(92,577) \mathrm{g} /$ day in South East Asia to $882(149,969) \mathrm{g} /$ day in East Asia. Only in South East Asia the weighted mean vegetable supply was below $240 \mathrm{~g} / \mathrm{day}$, whereas that of South Asia was just above the recommendations with $264 \mathrm{~g} /$ day.

\subsection{Europe}

Vegetable intake data was available for 37 out of 56 European countries and in four North European countries (Iceland, Denmark, Norway, Lithuania) legumes were included in the vegetable intake measurements. Weighted mean vegetable intake ranged from $123(95,207) \mathrm{g} /$ day in Western Europe to $270(83,382)$ in Eastern Europe (Table 1). Out of 37 European countries, four countries met the vegetable intake recommendations of $\geq 240 \mathrm{~g} / \mathrm{day}$, including one in Southern and three countries in Eastern Europe. The weighted mean vegetable supply ranged from $269(239,379) \mathrm{g} /$ day in Western Europe to $453(221,662) \mathrm{g} /$ day in Southern Europe. In 10 out of 36 countries, the vegetable supply was not sufficient to meet the recommended intake of $240 \mathrm{~g} /$ day.

\subsection{America}

Vegetable intake data was available for 28 out of 54 countries in the Americas. Weighted mean vegetable intake ranged from 56 (1-88) g/day in Central America to $156(48,263) \mathrm{g} /$ day in North America (Table 1). Of all the American countries, one South American country met the recommendations 
for vegetable intake. The weighted mean vegetable supply ranged from $102(53,252) \mathrm{g} /$ day in the Caribbean to $277(153,474) \mathrm{g}$ /day in North America. In Central and South America and the Caribbean the weighted mean vegetable supply was below $240 \mathrm{~g} / \mathrm{day}$, whereas in three out of four North American countries the vegetable supply was just above the recommendations with $277 \mathrm{~g} /$ day.

\subsection{Oceania}

Vegetable intake data was available for 18 out of 32 countries in Oceania. Weighted mean vegetable intake ranged from $73(64,248) \mathrm{g} /$ day in Melanesia to $196(72,417) \mathrm{g} /$ day in Polynesia (Table 1$)$. The vegetable intake met the recommendation in 2 of the 18 countries. The weighted mean vegetable supply ranged from $71(37,142) \mathrm{g} /$ day in Melanesia to $295(283,357) \mathrm{g} /$ day in Australasia. Only in Australasian countries the vegetable supply was above $240 \mathrm{~g} /$ day.

\subsection{Africa}

Vegetable intake data was available for 44 out of 62 countries in Africa. The weighted mean vegetable intake ranged from $98(28,304) \mathrm{g} /$ day in East African countries to $135(88,168) \mathrm{g} /$ day in South Africa (Table 1). In 3 out of the 44 African countries vegetable intake recommendations were met. The weighted mean vegetable supply ranged from $86(48,206) \mathrm{g} /$ day in East African countries to $434(230,531) \mathrm{g} /$ day in North Africa. Only in North Africa was the weighted mean vegetable supply sufficient to meet the recommendation of $240 \mathrm{~g} /$ day.

\section{Discussion}

Weighted mean vegetable intake was $186 \mathrm{~g} /$ day and ranged from $56 \mathrm{~g} /$ day in Central America to $349 \mathrm{~g} /$ day in East Asia. Weighted mean vegetable supply was $431 \mathrm{~g} /$ day and ranged widely among the different regions from $71 \mathrm{~g} /$ day in Melanesia to $882 \mathrm{~g} /$ day in East Asia. For $88 \%$ of the countries, vegetable intake was below the recommendations and for $61 \%$ the vegetable supply was too low to meet the recommendations of $240 \mathrm{~g} /$ day.

To our knowledge this is the first systematic review evaluating global vegetable intake (excluding legume and potato intake) at an individual level with a comparison to vegetable recommendation and vegetable supply. For $82 \%$ of the surveys/studies that were identified, vegetable intake data was compliant with the vegetable definition of FAO/WHO [53]. For $4 \%$ of the countries where fruit and vegetable intake were reported together, we made the assumption that $60 \%$ of the intake would come from vegetables, which may have resulted in either over- or underestimation of the intake. Only the most recent surveys of each country were selected, with $65 \%$ of the surveys/studies conducted in the last decade. Another important strength of this review is the high representativeness of the vegetable intake data, since for nearly $80 \%$ of the countries included the data extracted was nationally representative.

Limitations of our review with regard to the vegetable intake data are mainly due to heterogeneity among studies, including differences in the methods of assessing vegetable intake, differences in the definition of vegetable intake and differences in the units of reporting. For dietary intake of vegetables, the most common method was a (semi-)quantitative FFQ at individual level, which was used in $65 \%$ of the identified surveys/studies. A recent review on dietary intake measurements of vegetable and fruits in Europe, indicated also that FFQs were mostly used [3]. This review indicated that FFQs may differ in a number of aspects, such as (non)-itemization of terms, inclusion of potatoes and legumes in vegetable definition, and portion size calculation. This may also explain part of the variation in vegetable consumption between studies in our review. For instance, in many of the studies included in our review it was unclear whether soups, vegetable juices, processed vegetables and mixed dishes containing vegetables were included and hence vegetable intake may be underestimated. Furthermore, we noticed heterogeneity in calculation and reporting of vegetable intake data among the surveys that were using the STEPS methodology. Lastly, due to heterogeneity in reporting units, it was not possible to convert all data to means and SDs and hence it was not possible to calculate the prevalence 
of inadequate vegetable intake per country and region. Therefore, we decided to report vegetable intake in means and $95 \%$ CI.

Vegetable supply data may be underestimated as the data from FAO Food Balance Sheets are reported per capita and therefore comprise data for the entire population, including children. Furthermore, exclusion of vegetables that are cropped privately or in the wild $[53,66]$ and unavailability of production data of all regions within a country [66] in Food Balance Sheet data may have led to underestimation of vegetable supply. These limitations may partly explain the finding that for some countries the vegetable supply was lower than the intake. Other reasons for this finding can be attributed to limitations of the studies' measuring of vegetable intake, e.g., non-representativeness of intake data, lack of addressing seasonal differences in vegetable intake, and large differences between the year that the intake data were collected and the year of the supply data.

Our finding that vegetable intake worldwide is low ( $186 \mathrm{~g} /$ day) with many low- and middle-income countries in the range of 1-2 portions per day, correspond with that of earlier reviews. The GBD study of 2010 reported a mean intake of $209 \mathrm{~g} /$ day including legumes and starchy vegetables [49,50]. Similarly, the Prospective Urban Rural Epidemiology (PURE) study [51] and World Health Survey 2002-2003 [52] indicated that fruit and vegetable intake were below the recommendations and the intakes were generally lower in low- and middle income countries. One of the main reasons for the low vegetable intake in the low- and middle-income countries is urbanization and shift to a more "western" diet, high in foods that are high in sugar, fat, and salt and low in fiber. In addition, in these countries there is generally a lack of secure availability and affordability of vegetables, which are underlying causes for an inadequate intake of vegetables [51].

An important finding of our review is that even though the weighted vegetable supply worldwide is sufficient (431 g/day), vegetable supply among the countries varies widely and consequently in many countries it is insufficient to adhere to the recommended intake of $240 \mathrm{~g} / \mathrm{day}$. With a shift to a more plant-based diet, as recently recommended by the EAT-Lancet commission, vegetable intake recommendations are further increasing to $300 \mathrm{~g} /$ day [67]. This would imply that in the vast majority (93\%) of the countries globally, vegetable supply would not be sufficient. The EAT-Lancet commission predicts that an increase of $75 \%$ in production of vegetables is needed together with accompanying measures to prevent losses in vegetable supply, e.g., preservation techniques such as drying, canning and freezing of vegetables. Moreover, improvements in the infrastructure are needed to facilitate the distribution of vegetables and innovative approaches to improve accessibility of fresh vegetables to consumers are essential to improve vegetable consumption.

To further improve vegetable intake, consumers should be educated about the benefits of vegetables for health. International recommendations should become more specific concerning the categories included and the portion sizes of raw and cooked vegetables. The development of country specific food based dietary guidelines including a recommendation for vegetable intake can play a role in this, although many countries have not yet developed these or the recommendation is unclear [68]. Subsequently, the national nutrition policy makers could develop detailed guidelines which are in line with the international guidelines by WHO/FAO and translated to the dietary goals and traditions of the country. These guidelines should include practical examples of traditional cooking methods and recipes to increase vegetable intake. Moreover, community-based activities like community kitchens could be organized [69]. The objective would be to educate the populations about healthy dietary patterns according to national dietary guidelines, including the importance of vegetables and vegetable categories, and to improve cooking and purchasing skills adapted to the national and regional culture. While the effectiveness of public health interventions to increase vegetable intake through education and counseling is mostly positive, unclarity exists about whether the achievements remain in the longer term [70-72]. In order to change the behavior of the consumer, it is important that the environment should be encouraging and rewarding. Besides an adequate supply and accessibility, affordability of vegetables is key. The PURE study (2016) indicated that low income countries spend a higher percentage of the households' income on vegetables compared to high income countries [51]. 
Governments need to play a role to ensure that vegetables become affordable to the entire population, including the lower income consumers. A modelling study estimated that, even under optimistic socioeconomic scenarios with economic growth, the future supply of vegetables will be insufficient to meet the recommendations for many countries [73]. This prediction makes even more imperative the need to tackle the global problem of food loss and waste, especially in the case of vegetables that are considered sensitive food products and whose loss can easily occur due to poor practices and degradation [74]. Nevertheless, locally grown and sourced vegetables, and inclusion of indigenous vegetables may help to ensure a fresh and sustainable vegetable supply. Furthermore, learning from public health strategies aimed at increasing vegetable intake in the countries with an adequate vegetable intake should be taken into account.

Lastly, it would be beneficial to get a better understanding of the health properties of the different vegetables and how different processing techniques will influence the effect of vegetables on health. This could lead to more detailed guidance on vegetable consumption; for instance, in the German guidelines, specific recommendations were provided for raw and cooked vegetables. In order to monitor whether populations adhere to the guidelines and to allow for country comparisons, harmonization of the methodology used to collect vegetable intake data, including standard dietary methods and measurement units, is recommended.

\section{Conclusions}

In conclusion, our review indicated that global vegetable intake is generally below the recommendations of $240 \mathrm{~g} /$ day and that the vegetable supply is mostly inadequate to meet the recommendations. With the current emphasis on consuming plant-based diets, efforts are needed to improve the production, accessibility and affordability of vegetables in conjunction with innovative approaches to establish a sustained behavior change aimed at improving vegetable intake worldwide.

Supplementary Materials: The following are available online at http://www.mdpi.com/2072-6643/12/6/1558/s1, Table S1: PRISMA checklist, Table S2: Vegetable intake, socio-demographics, sample size and representativeness, vegetable intake data source and dietary method used per country.

Author Contributions: Conceptualization, A.K., A.E. and E.T.; methodology, A.K., A.E. and E.F.T.; formal analysis, A.K.; investigation, A.K.; data curation, A.K. and A.E.; writing-original draft preparation, A.K. and A.E.; writing-review and editing, A.E., A.K. and E.F.T.; visualization, A.K.; supervision, A.K. and E.F.T. All authors have read and agreed to the published version of the manuscript.

Funding: This research was partly conducted as internship project of A.K., which was funded by Unilever. The APC was funded by Wageningen University and Research.

Conflicts of Interest: A.E. is employee of Unilever. The other authors do not have a conflict of interest.

\section{References}

1. Darfour-Oduro, S.A.; Buchner, D.M.; Andrade, J.E.; Grigsby-Toussaint, D.S. A comparative study of fruit and vegetable consumption and physical activity among adolescents in 49 Low-and-Middle-Income Countries. Sci. Rep. 2018, 8, 1623. [CrossRef]

2. Diet, nutrition and the prevention of chronic diseases. World Health Organ. Tech. Rep. Ser. 2003, 916. i-viii, 1-149, backcover.

3. Riordan, F.; Ryan, K.; Perry, I.J.; Schulze, M.B.; Andersen, L.F.; Geelen, A.; Van't Veer, P.; Eussen, S.; Dagnelie, P.; Wijckmans-Duysens, N.; et al. A systematic review of methods to assess intake of fruits and vegetables among healthy European adults and children: A DEDIPAC (DEterminants of DIet and Physical Activity) study. Public Health Nutr. 2017, 20, 417-448. [CrossRef] [PubMed]

4. Riley, L.; Guthold, R.; Cowan, M.; Savin, S.; Bhatti, L.; Armstrong, T.; Bonita, R. The World Health Organization STEPwise Approach to Noncommunicable Disease Risk-Factor Surveillance: Methods, Challenges, and Opportunities. Am. J. Public Health 2016, 106, 74-78. [CrossRef] [PubMed]

5. Health Organization, W. Global Health Risks. Mortality and Burden Och Disease Attributable to Selected Major Risks; Health Organization: Geneva, Switzerland, 2009; pp. 1-63. 
6. Dauchet, L.; Amouyel, P.; Hercberg, S.; Dallongeville, J. Fruit and vegetable consumption and risk of coronary heart disease: A meta-analysis of cohort studies. J. Nutr. 2006, 136, 2588-2593. [CrossRef]

7. Joshipura, K.J.; Hu, F.B.; Manson, J.E.; Stampfer, M.J.; Rimm, E.B.; Speizer, F.E.; Colditz, G.; Ascherio, A.; Rosner, B.; Spiegelman, D.; et al. The effect of fruit and vegetable intake on risk for coronary heart disease. Ann. Intern. Med. 2001, 134, 1106-1114. [CrossRef]

8. Oyebode, O.; Gordon-Dseagu, V.; Walker, A.; Mindell, J.S. Fruit and vegetable consumption and all-cause, cancer and CVD mortality: Analysis of Health Survey for England data. J. Epidemiol. Commun. Health 2014, 68, 856-862. [CrossRef] [PubMed]

9. Lock, K.; Pomerleau, J.; Causer, L.; Altmann, D.R.; McKee, M. The global burden of disease attributable to low consumption of fruit and vegetables: Implications for the global strategy on diet. Bull World Health Organ 2005, 83, 100-108.

10. He, F.J.; Nowson, C.A.; Lucas, M.; MacGregor, G.A. Increased consumption of fruit and vegetables is related to a reduced risk of coronary heart disease: Meta-analysis of cohort studies. J. Hum. Hypertens. 2007, $21,717$. [CrossRef]

11. He, F.J.; Nowson, C.A.; MacGregor, G.A. Fruit and vegetable consumption and stroke: Meta-analysis of cohort studies. Lancet 2006, 367, 320-326. [CrossRef]

12. Hu, D.; Huang, J.; Wang, Y.; Zhang, D.; Qu, Y. Fruits and Vegetables Consumption and Risk of Stroke. Meta-Anal. Prospect. Cohort Stud. 2014, 45, 1613-1619. [CrossRef]

13. Crowe, F.; W Roddam, A.; J Key, T.; N Appleby, P.; Overvad, K.; Jakobsen, M.; Tjønneland, A.; Hansen, L.; Boeing, H.; Weikert, C.; et al. Fruit and Vegetable Intake and Mortality from Ischaemic Heart Disease: Results from the European Prospective Investigation into Cancer and Nutrition (EPIC)-Heart Study. Eur. Heart J. 2011, 32, 1235-1243. [CrossRef] [PubMed]

14. Borgi, L.; Muraki, I.; Satija, A.; Willett, W.C.; Rimm, E.B.; Forman, J.P. Fruit and Vegetable Consumption and the Incidence of Hypertension in Three Prospective Cohort Studies. Hypertension 2016, 67, 288-293. [CrossRef] [PubMed]

15. Li, B.; Li, F.; Wang, L.; Zhang, D. Fruit and Vegetables Consumption and Risk of Hypertension: A Meta-Analysis. J. Clin. Hypertens. (Greenwich Conn,) 2016, 18, 468-476. [CrossRef] [PubMed]

16. Bhupathiraju, S.N.; Wedick, N.M.; Pan, A.; Manson, J.E.; Rexrode, K.M.; Willett, W.C.; Rimm, E.B.; Hu, F.B. Quantity and variety in fruit and vegetable intake and risk of coronary heart disease. Am. J. Clin. Nutr. 2013, 98, 1514-1523. [CrossRef]

17. Dauchet, L.; Amouyel, P.; Dallongeville, J. Fruit and vegetable consumption and risk of stroke: A meta-analysis of cohort studies. Neurology 2005, 65, 1193-1197. [CrossRef]

18. Zhan, J.; Liu, Y.J.; Cai, L.B.; Xu, F.R.; Xie, T.; He, Q.Q. Fruit and vegetable consumption and risk of cardiovascular disease: A meta-analysis of prospective cohort studies. Crit. Rev. Food Sci. Nutr. 2017, 57, 1650-1663. [CrossRef]

19. Kaiser, K.A.; Brown, A.W.; Bohan Brown, M.M.; Shikany, J.M.; Mattes, R.D.; Allison, D.B. Increased fruit and vegetable intake has no discernible effect on weight loss: A systematic review and meta-analysis. Am. J. Clin. Nutr. 2014, 100, 567-576. [CrossRef]

20. Tapsell, L.C.; Dunning, A.; Warensjo, E.; Lyons-Wall, P.; Dehlsen, K. Effects of vegetable consumption on weight loss: A review of the evidence with implications for design of randomized controlled trials. Am. J. Clin. Nutr. 2014, 54, 1529-1538. [CrossRef]

21. Ledoux, T.A.; Hingle, M.D.; Baranowski, T. Relationship of fruit and vegetable intake with adiposity: A systematic review. Obes. Rev. 2011, 12, e143-e150. [CrossRef]

22. Carter, P.; Gray, L.J.; Troughton, J.; Khunti, K.; Davies, M.J. Fruit and vegetable intake and incidence of type 2 diabetes mellitus: Systematic review and meta-analysis. BMJ (Clin. res. ed.) 2010, 341. [CrossRef]

23. Harding, A.H.; Wareham, N.J.; Bingham, S.A.; Khaw, K.; Luben, R.; Welch, A.; Forouhi, N.G. Plasma vitamin $\mathrm{C}$ level, fruit and vegetable consumption, and the risk of new-onset type 2 diabetes mellitus: The European prospective investigation of cancer-Norfolk prospective study. Arch. Intern. Med. 2008, 168, 1493-1499. [CrossRef] [PubMed]

24. Villegas, R.; Shu, X.O.; Gao, Y.T.; Yang, G.; Elasy, T.; Li, H.; Zheng, W. Vegetable but not fruit consumption reduces the risk of type 2 diabetes in Chinese women. J. Nutr. 2008, 138, 574-580. [CrossRef] [PubMed]

25. Bazzano, L.A.; Li, T.Y.; Joshipura, K.J.; Hu, F.B. Intake of fruit, vegetables, and fruit juices and risk of diabetes in women. Diabetes Care 2008, 31, 1311-1317. [CrossRef] [PubMed] 
26. Montonen, J.; Jarvinen, R.; Heliovaara, M.; Reunanen, A.; Aromaa, A.; Knekt, P. Food consumption and the incidence of type II diabetes mellitus. Eur. J. Clin. Nutr. 2005, 59, 441-448. [CrossRef] [PubMed]

27. Liu, S.; Serdula, M.; Janket, S.J.; Cook, N.R.; Sesso, H.D.; Willett, W.C.; Manson, J.E.; Buring, J.E. A prospective study of fruit and vegetable intake and the risk of type 2 diabetes in women. Diabetes Care 2004, 27, 2993-2996. [CrossRef] [PubMed]

28. Ford, E.S.; Mokdad, A.H. Fruit and vegetable consumption and diabetes mellitus incidence among U.S. adults. Prev. Med. 2001, 32,33-39. [CrossRef]

29. Meyer, K.A.; Kushi, L.H.; Jacobs, D.R., Jr.; Slavin, J.; Sellers, T.A.; Folsom, A.R. Carbohydrates, dietary fiber, and incident type 2 diabetes in older women. J. Clin. Nutr. 2000, 71,921-930. [CrossRef]

30. Hirayama, F.; Lee, A.H.; Binns, C.W.; Zhao, Y.; Hiramatsu, T.; Tanikawa, Y.; Nishimura, K.; Taniguchi, H. Do vegetables and fruits reduce the risk of chronic obstructive pulmonary disease? A case-control study in Japan. Prev. Med. 2009, 49, 184-189. [CrossRef]

31. Hosseini, B.; Berthon, B.S.; Wark, P.; Wood, L.G. Effects of Fruit and Vegetable Consumption on Risk of Asthma, Wheezing and Immune Responses: A Systematic Review and Meta-Analysis. Nutrients 2017, 9. [CrossRef]

32. Soerjomataram, I.; Oomen, D.; Lemmens, V.; Oenema, A.; Benetou, V.; Trichopoulou, A.; Coebergh, J.W.; Barendregt, J.; de Vries, E. Increased consumption of fruit and vegetables and future cancer incidence in selected European countries. Eur. J. Cancer 2010, 46, 2563-2580. [CrossRef] [PubMed]

33. Leenders, M.; Siersema, P.D.; Overvad, K.; Tjonneland, A.; Olsen, A.; Boutron-Ruault, M.C.; Bastide, N.; Fagherazzi, G.; Katzke, V.; Kuhn, T.; et al. Subtypes of fruit and vegetables, variety in consumption and risk of colon and rectal cancer in the European Prospective Investigation into Cancer and Nutrition. Int. J. Cancer 2015, 137, 2705-2714. [CrossRef] [PubMed]

34. Benetou, V.; Orfanos, P.; Lagiou, P.; Trichopoulos, D.; Boffetta, P.; Trichopoulou, A. Vegetables and fruits in relation to cancer risk: Evidence from the Greek EPIC cohort study. Cancer Epidemiol. Biomark. Prev. 2008, 17, 387-392. [CrossRef] [PubMed]

35. Linseisen, J.; Rohrmann, S.; Miller, A.B.; Bueno-de-Mesquita, H.B.; Buchner, F.L.; Vineis, P.; Agudo, A.; Gram, I.T.; Janson, L.; Krogh, V.; et al. Fruit and vegetable consumption and lung cancer risk: Updated information from the European Prospective Investigation into Cancer and Nutrition (EPIC). Int. J. Cancer 2007, 121, 1103-1114. [CrossRef]

36. Gonzalez, C.A.; Pera, G.; Agudo, A.; Bueno-de-Mesquita, H.B.; Ceroti, M.; Boeing, H.; Schulz, M.; Del Giudice, G.; Plebani, M.; Carneiro, F.; et al. Fruit and vegetable intake and the risk of stomach and oesophagus adenocarcinoma in the European Prospective Investigation into Cancer and Nutrition (EPIC-EURGAST). Int. J. Cancer 2006, 118, 2559-2566. [CrossRef]

37. Takachi, R.; Inoue, M.; Sugawara, Y.; Tsuji, I.; Tsugane, S.; Ito, H.; Matsuo, K.; Tanaka, K.; Tamakoshi, A.; Mizoue, T.; et al. Fruit and vegetable intake and the risk of overall cancer in Japanese: A pooled analysis of population-based cohort studies. J. Epidemiol. 2017, 27, 152-162. [CrossRef]

38. Wang, M.; Qin, S.; Zhang, T.; Song, X.; Zhang, S. The effect of fruit and vegetable intake on the development of lung cancer: A meta-analysis of 32 publications and 20414 cases. Eur. J. Clin. Nutr. 2015, 69, 1184. [CrossRef]

39. Li, M.; Fan, Y.; Zhang, X.; Hou, W.; Tang, Z. Fruit and vegetable intake and risk of type 2 diabetes mellitus: Meta-analysis of prospective cohort studies. BMJ Open 2014, 4, e005497. [CrossRef]

40. Appleton, K.M.; Hemingway, A.; Saulais, L.; Dinnella, C.; Monteleone, E.; Depezay, L.; Morizet, D.; Armando Perez-Cueto, F.J.; Bevan, A.; Hartwell, H. Increasing vegetable intakes: Rationale and systematic review of published interventions. Eur. J. Nutr. 2016, 55, 869-896. [CrossRef]

41. Liu, R.H. Health-promoting components of fruits and vegetables in the diet. Adv. Nutr. 2013, 4, 384S-392S. [CrossRef]

42. Slavin, J.L.; Lloyd, B. Health Benefits of Fruits and Vegetables. Adv. Nutr. 2012, 3, 506-516. [CrossRef] [PubMed]

43. Sharma, S.; Sheehy, T.; Kolonel, L. Sources of vegetables, fruits, and vitamins A, C and E among five ethnic groups: Results from the Multiethnic Cohort Study. Eur. J. Clin. Nutr. 2014, 68, 384-391. [CrossRef] [PubMed]

44. Flood-Obbagy, J.E.; Rolls, B.J. The effect of fruit in different forms on energy intake and satiety at a meal. Appetite 2009, 52, 416-422. [CrossRef] [PubMed] 
45. Van Duyn, M.A.S.; Pivonka, E. Overview of the Health Benefits of Fruit and Vegetable Consumption for the Dietetics Professional: Selected Literature. J. Am. Diet. Assoc. 2000, 100, 1511-1521. [CrossRef]

46. Pem, D.; Jeewon, R. Fruit and Vegetable Intake: Benefits and Progress of Nutrition Education InterventionsNarrative Review Article. Iran. J. Public Health 2015, 44, 1309-1321. [PubMed]

47. Loef, M.; Walach, H. Fruit, vegetables and prevention of cognitive decline or dementia: A systematic review of cohort studies. J. Nutr. Health Aging 2012, 16, 626-630.

48. World Health Organization. Food and Agriculture Organization of the United Nations. Diet, Nutrition, and the Prevention of Chronic Diseases: Report of a Joint WHO/FAO Expert Consultation; World Health Organization: Geneva, Switzerland, 2003; p. 149.

49. Micha, R.; Khatibzadeh, S.; Shi, P.; Andrews, K.G.; Engell, R.E.; Mozaffarian, D. Global, regional and national consumption of major food groups in 1990 and 2010: A systematic analysis including 266 country-specific nutrition surveys worldwide. BMJ Open 2015, 5. [CrossRef]

50. Global, regional, and national incidence, prevalence, and years lived with disability for 328 diseases and injuries for 195 countries, 1990-2016: A systematic analysis for the Global Burden of Disease Study 2016. Lancet 2017, 390, 1211-1259. [CrossRef]

51. Miller, V.; Yusuf, S.; Chow, C.K.; Dehghan, M.; Corsi, D.J.; Lock, K.; Popkin, B.; Rangarajan, S.; Khatib, R.; Lear, S.A.; et al. Availability, affordability, and consumption of fruits and vegetables in 18 countries across income levels: Findings from the Prospective Urban Rural Epidemiology (PURE) study. Lancet Glob. Health 2016, 4, e695-e703. [CrossRef]

52. Hall, J.N.; Moore, S.; Harper, S.B.; Lynch, J.W. Global variability in fruit and vegetable consumption. Am. J. Prev. Med. 2009, 36, 402-409. [CrossRef]

53. Agudo, A. Measuring Intake of fruit and Vegetables [electronic resource] / Antonio Agudo; World Health Organization: Geneva, Switzerland.

54. Food-Based Dietary Guidelines. Available online: http://www.fao.org/nutrition/education/food-dietaryguidelines/home/en/ (accessed on 15 March 2018).

55. Research, W.C.R.F.A.I.f.C. Food, Nutrition, Physical Activity, and the Prevention of Cancer: A Global Perspective; American Institute for Cancer Research: Washington, DC, USA, 2007.

56. Moher, D.; Liberati, A.; Tetzlaff, J.; Altman, D.G. Preferred reporting items for systematic reviews and meta-analyses: The PRISMA statement. BMJ 2009, 339. [CrossRef] [PubMed]

57. Nag, O.S. The Regions Of Europe. 13 March. Available online: https://www.worldatlas.com/articles/ the-four-european-regions-as-defined-by-the-united-nations-geoscheme-for-europe.html (accessed on 13 March 2018).

58. Sawe, B.E. What Is The United Nations Geoscheme? Available online: https://www.worldatlas.com/articles/ what-is-the-united-nations-geoscheme.html (accessed on 13 March 2018).

59. EFSA. The EFSA Comprehensive European Food Consumption Database. Available online: https://www. efsa.europa.eu/en/food-consumption/comprehensive-database (accessed on 20 June 2019).

60. Hilger, J.; Friedel, A.; Herr, R.; Rausch, T.; Roos, F.; Wahl, D.A.; Pierroz, D.D.; Weber, P.; Hoffmann, K. A systematic review of vitamin D status in populations worldwide. Br. J. Nutr. 2014, 111, 23-45. [CrossRef] [PubMed]

61. Hozo, S.P.; Djulbegovic, B.; Hozo, I. Estimating the mean and variance from the median, range, and the size of a sample. BMC Med. Res. Methodol. 2005, 5, 13. [CrossRef] [PubMed]

62. Wan, X.; Wang, W.; Liu, J.; Tong, T. Estimating the sample mean and standard deviation from the sample size, median, range and/or interquartile range. BMC Med. Res. Methodol. 2014, 14, 135. [CrossRef] [PubMed]

63. Barde, M.P.; Barde, P.J. What to use to express the variability of data: Standard deviation or standard error of mean? Perspect. Clin. Res. 2012, 3, 113-116. [CrossRef] [PubMed]

64. (UNICEF), U.N.C.s.F. The State of the World's Children 2015: Executive Summary. Reimagine the Future. Innovation for Every Child; UNICEF: New York, NY, USA, 2014.

65. Food Balance Sheets. Available online: http://www.fao.org/economic/ess/fbs/en/ (accessed on 15 July 2019).

66. Introduction. In Food Balance Sheets- A Handbook; FAO (Ed.) FAO: Rome, Italy, 2001.

67. Willett, W.; Rockström, J.; Loken, B.; Springmann, M.; Lang, T.; Vermeulen, S.; Garnett, T.; Tilman, D.; DeClerck, F.; Wood, A.; et al. Food in the Anthropocene: The EAT-Lancet Commission on healthy diets from sustainable food systems. Lancet 2019, 393, 447-492. [CrossRef] 
68. Herforth, A.; Arimond, M.; Alvarez-Sanchez, C.; Coates, J.; Christianson, K.; Muehlhoff, E. A Global Review of Food-Based Dietary Guidelines. Adv. Nutr. 2019, 10, 590-605. [CrossRef]

69. Institute of Medicine (US) and National Research Council (US) Committee on Childhood Obesity Prevention Actions for Local Governments. Actions for Healthy Eating. In Local Government Actions to Prevent Childhood Obesity; Parker L, B.A., Sanchez, E., Eds.; National Academies Press (US): Washington, DC, USA, 2009.

70. Pomerleau, J.; Lock, K.; Knai, C.; McKee, M. Interventions designed to increase adult fruit and vegetable intake can be effective: A systematic review of the literature. J. Nutr. 2005, 135, 2486-2495. [CrossRef]

71. Conner, T.S.; Brookie, K.L.; Carr, A.C.; Mainvil, L.A.; Vissers, M.C.M. Let them eat fruit! The effect of fruit and vegetable consumption on psychological well-being in young adults: A randomized controlled trial. PLoS ONE 2017, 12, e0171206. [CrossRef]

72. Plaete, J.; Crombez, G.; Van der Mispel, C.; Verloigne, M.; Van Stappen, V.; De Bourdeaudhuij, I. Effect of the Web-Based Intervention MyPlan 1.0 on Self-Reported Fruit and Vegetable Intake in Adults Who Visit General Practice: A Quasi-Experimental Trial. J. Med. Internet Res. 2016, 18, e47. [CrossRef]

73. Mason-D'Croz, D.; Bogard, J.R.; Sulser, T.B.; Cenacchi, N.; Dunston, S.; Herrero, M.; Wiebe, K. Gaps between fruit and vegetable production, demand, and recommended consumption at global and national levels: An integrated modelling study. Lancet. Planet. Health 2019, 3, e318-e329. [CrossRef]

74. Ishangulyyev, R.; Kim, S.; Lee, S.H. Understanding Food Loss and Waste-Why Are We Losing and Wasting Food? Foods 2019, 8, 297. [CrossRef] [PubMed]

(C) 2020 by the authors. Licensee MDPI, Basel, Switzerland. This article is an open access article distributed under the terms and conditions of the Creative Commons Attribution (CC BY) license (http://creativecommons.org/licenses/by/4.0/). 